\title{
Existing Dilemma of the Impact of Eucalyptus Species on Crop Yield and Soil Nutrients in Ethiopia: Review Paper
}

\author{
Bayu Belayneh \\ Bahir Dar Environment and Forest Research Center. P.O.Box 2128. Bahir Dar, Ethiopia
}

\begin{abstract}
Eucalyptus is an ever green fast-growing tree species which is introduced in Ethiopia during the regime of Emperor Menelik II to solve the scarcity of wood products especially for fuel wood and construction materials. Eucalyptus is widely planted in Ethiopia due to the economic benefit and special nature of the species such as, it needs minimum care, fast growing, good for fuel and construction material and easily propagation. However, there is dilemma the impact of Eucalyptus on crop yield and soil nutrients. Therefore, this review focused on the influence of eucalyptus species on crop productivity and soil nutrients. Several studies reported that planting of Eucalyptus species nearby or alongside of crop growing areas reduces the productivity of crops by up taking more nutrients and water as compared to neighbouring species whereas, another studies reported that higher crop yield and soil nutrients were obtained from crops growing in the clear-felling eucalyptus stands as compared to continuous cultivated crop lands. In conclusion, Eucalyptus has a negative and positive influence on soil nutrients and crop yield depends on the management planning and tending operation of the species. Therefore, to reduce the adverse effect of eucalyptus giving more attention on its management is very vital.
\end{abstract}

Keywords: wood products, fast growing, economic benefit, fuel wood

DOI: $10.7176 / \mathrm{JNSR} / 11-17-01$

Publication date:September $30^{\text {th }} 2020$

\section{Introduction}

Ethiopia begins planting Eucalyptus species in the year of 1890s, at that time there was a plantation plan to establish vigorous and fast-growing trees similar to Eucalyptus (Lemenih, 2008). Since 1890s Eucalyptus tree has highly planted every year due to the rising demand of the people for fuel wood and construction materials. To manage through the exceedingly scarcity of wood products, primarily fuel wood, more than 100,000 ha of land covered by Eucalyptus globules plantations (Pohjonen and Pukkala, 1990). Currently, in Ethiopia huge amount of lands covered by Eucalyptus plantation while the deforestation rate of inhabitant forests is increased due to the demand for crop and grazing lands (Abebe and Tadesse, 2014). Eucalyptus species extremely planted in Ethiopia because it provides more energy compared to other species which existing in the country (Teketay, 2000; Pohjonen and Pukkala, 1990). Similarly, in order to fulfil the demand of energy in the nation by 2014, 6 percent of the whole utilizable area should cover to be set under Eucalyptus plantations (Kidanu et al., 2005) needing a main change in land utilization. Therefore, introducing fast growing and multiple product tree species that could be combining with yearly crops may be a significant value in addressing the existing biomass energy shortage in Ethiopia (Kidanu et al., 2005). Eucalyptus plantations are extensively managed for wood production in Ethiopia. Concurrently, traditional agro forestry practices in Ethiopia needs tree planting in different ways to get multiple values for farmers like wood (fuel wood and constriction material) and fodder (Kidanu et al., 2005). The growing demand for construction material and fuel wood, and the wider adaptation potential of Eucalyptus in to different agro-ecological zones resulting increased plantation of Eucalyptus by smallholders in the country. However, the policy in Ethiopia discourages farmers from planting this exotic species, locality level politicians opposed it's planting, and researchers had doubts about it. The opposition of the politicians appears to be founded on fears of damage to the ecosystem (Mekonnen et al., 2007). Eucalyptus is the well-known tree in regime and community state plantations because of its easily propagation through coppicing, resistance to browsing by livestock, and rapid growth rate (Pohjonen and Pukkala, 1990). The yearly wood production rate, which was 345-903 kg ha_1 yr_1 with two- and four-year-old stands in the first cycle, was increased more than 2 -fold in the subsequent two rotation cycles. With these productivities, eucalyptus boundaries on a hectare of land in the second and third cycle would satisfy about $70 \%$ of the annual biomass energy requirement of a rural household with a family size of five people for four consecutive years (Kidanu et al., 2005).

Currently, Ethiopia has so many Eucalyptus species but the most common and well-known Eucalyptus species are Eucalyptus globulus Labill., Eucalyptus camaldulensis Dehnn., Eucalyptus saligna Sm., Eucalyptus grandis W. Hill ex Maid. and Eucalyptus tereticornis Sm. Planting Eucalyptus is increasing from state owned forestry enterprises and projects to community woodlots, household and farm field boundaries. For example, Eucalyptus globulus trees are planted in croplands along the border and it comes to control the Ethiopian landscape (Kidanu et al., 2005). This species is unpalatable to cattle, sheep and goats (Pohjonen and Pukkala, 1990) and have different benefit as a boundary planting in the Ethiopian highlands (Kidanu et al., 2005). Eucalyptus species are relatively fast growing and profitable as compared to other tree species. The rates of return for farmers' investments 
in Eucalyptus plantation are often more than 20\% (Jagger and Pender, 2003).

But, despite on its economic benefit, most of the studies shows that the species has adverse effect on the crop yield and soil nutrients when it grows mixed with crop lands. There is evidence that competition for water and nutrients are always exist when we grow two or more plants in the same field. Consequently, production of agricultural crops which is grown nearby Eucalyptus plantation significantly decline due to the competition of available resources like water, light and nutrient, and shading effect (Gindaba, 2003; Kidanu et al., 2004; Chanie et al., 2013). According to Chanie et al., (2013) crop yield and soil nutrient reduction occurred up to $15 \mathrm{~m}$ distance from the eucalyptus plantation. On the other hand the work of Desalegn et al., (2014) suggested that the higher crop yield was obtained from the land which was previously cultivated eucalyptus lands as compared to the continuous crop cultivation lands. Similarly, the higher soil chemical properties and organic matter were recorded from the land previously cultivated eucalyptus land as compared to the adjust crop lands (Birru et al., 2013).

Such uncertainty on ecological implications of exotic trees like Eucalyptus species, which have been used for industrial purpose as well as for agro-forestry are often rise questioned since their ecology has not been appropriately studied (Bernhard- Reversat, 1999). Therefore, the overall aim of this review is to show the influence of eucalyptus species on crop yield and soil nutrients in Ethiopia.

\section{Effect of Eucalyptus Plantation on Crop Yield}

Several studies reported that Eucalyptus plantation significantly affects crop production by utilizing readily available nutrients for rapid growth, which leads to reduce available minerals for crops (Jagger and Pender, 2003; Gindaba, 2003; Kidanu et al., 2004; Chanie et al., 2013; Khybri et al., 1992; Malik and Sharma, 1990). Seedlings of Eucalyptus are vulnerable to severe water stress unlike the seedlings of different tree species in Ethiopia (Gindaba et al., 2004). This indicates that Eucalyptus trees need more water and compete with neighboring plants for the availability of water in the soil. For example, the total biomass of crops grown nearby Eucalyptus stand was reduced due to the decline of soil nutrients and shading effect of the eucalyptus (Chanie et al., 2013; Kidanu et al., (2004). In line with this low water availability is occurred in the soil in the tree-crop interaction land as compared to mono cropping system (Kidanu and Stonier, 2004). The nearest crop plants were wilted unlike the farther stands since Eucalyptus competes for moisture even deeper in the soil. Similarly, light availability and intensity had a significant effect on crop biomass as compared to water availability (Kotowskil et al., 2000). Furthermore, studies in Sudan reveled that high crop yield reduction was recorded nearby Eucalyptus stands due to nutrient depletion and production of toxic exudates (allelochemicals) (EI-Amin et al., (2001). Watson, (2000) also stated Eucalyptus leaf extracts have inhibited the germination of several plants. Therefore, Eucalyptus species caused drawbacks rather than improving the performance of the undergrowth vegetation. Moreover, Eucalyptus trees affected the maize plant performance by reducing available $p$ even if the strength of belowground competition can be decreased with fertilization (James, 1999). Lane et al., (2004) found in China described that the expansion of Eucalyptus plantation on lands previously used for crops and occupied by indigenous trees and grass lowers water tables and reduces water availability for irrigation due to soil hydrophobicity (water repellency) and its deep and dense root network. The work of EI-Amin et al., (2001) also suggested that Eucalyptus plantation have significant effect on soil nutrients and crop productivity but the effects depends on the species, type of site and management activities.

On the other hand growing of crops on previously Eucalyptus cultivated stands are produce higher crop yield than the continuous cultivated cropping lands (Desalegn et al., 2014). The higher yield obtained from the previously planted eucalyptus stand is maybe due to the higher nutrient content of the stand. Because, studies indicated that soil chemical properties and organic matter were improved when the land is changed from eucalyptus stand to crop lands (Birru et al., 2013). Similarly, higher soil nutrients and organic carbon were obtained in plantations of Eucalyptus grandis compared with adjacent natural forest (Alem et al., 2010). Generally, it is not recommended growing the mixture of eucalyptus with agricultural crops simultaneously in the same land due to their competition for water and nutrients, and the shade effect. However, based on the above findings using rotation system of crop and Eucalyptus maybe more effective for crop production and economic benefits for small holder farmers.

\section{Effects of Eucalyptus Plantation on Soil Nutrient}

Many studies have been made in different parts of the world concerning the effects of Eucalyptus plantation on soil and other related environmental conditions, most of the studies focused on soil property changes under the plantations (Janice, 2016; Chanie et al., 2013; Palmberg, 2002; Jagger and pender, 2003; Sunder, 1993; Poore and Friss, 1985). These Studies reported that Eucalyptus has a significant effect on soil nutrients like total Nitrogen, available phosphorus (avail. P), exchangeable calcium (exch. Ca), moisture content (MC). Similarly, the soil pH as well as base saturation exhibited a clear decrease under Eucalyptus compared to adjacent natural forest and other exotic tree species (Lemenih, 2004). In recent years, soil degradation in Ethiopia has serious problem many soils are poor in nutrient and suitable for erosion. The main causes for soil degradation are poor agricultural 
practices, deforestation and overgrazing, but also the poorly planned and management of fast-growing tree plantations may leads to soil quality decline (Lemma, 2006). Fast growing tree species are required more nutrient for growth compared to slow growing species. Eucalyptus is fast growing tree uptakes more nutrient from the soil (Zegeye, 2010; Cole and Rapp, 1981). The work of Heilman \& Norby, (1997) and Zerfu, (2002) revealed that higher soil nutrient removal were occurred during the harvesting time because Eucalyptus is fast growing and has short harvesting rotation time. Further, Turner \& Lambert, (2000) observed as soil nutrient is decreased in eucalyptus cultivation land as compared to the adjacent native forests in south-eastern Brazil. Since Eucalyptus species are fast growing, and deep and dense rooted, the reducing and drying status of previously functional nearby water stores in the agricultural land is as a result of its greatest water sucking ability as well soil hydrophobicity and poor undergrowth leading the reduction of infiltration capacity and water table.

However, recent studies reported that Eucalyptus plantation has enhanced the soil chemical properties and soil organic matter as compared to the adjacent crop production lands. For example, the work of (Birru et al., 2013) suggested that soil chemical properties and organic matters were better in the previously cultivated eucalyptus land as compared to continuously cultivation crop lands. Therefore, changing eucalyptus land to crop land is possible without affecting the soil properties and crop productivity. In line with this rotating crop lands with Eucalypts can improve soil productivity via translocation of nutrients from deeper horizons to the soil surface (Tchienkoua and Zech, 2004). Further, higher soil nutrients and organic carbon were obtained in plantations of Eucalyptus grandis compared with adjacent natural forest (Alem et al., 2010). Based on the results improving the management operation of eucalyptus stands is very important to increase the positive feedback of the species for soil nutrients.

\section{Allelophatic Effects of Eucalyptus}

Allelopathy is a biological process of plants which is producing one or more chemicals hat influence the germination, growth, survival, and reproduction of other plants. Eucalypts trees have allelophatic and inhibiting effect on undergrowth plant regeneration and growth by secreting different types of chemicals, from their leaves, stems and roots such as, phenolics terpenoids (Ahmed et al., 2008; Zhang, 2009; Lisanework and Michelsen, 1993; Poore and Fries, 1985). For instance, EI-Amin et al., (2001) in Sudan reported that Eucalyptus caused crop yield reduction due to nutrient depletion and production of toxic exudates (allelochemicals). Similarly, the above and underground extracts of Eucalyptus camaldulensis could affect germination and early seedling growth of undergrowth plants and crops (Saberi et al. 2013). Moreover, the leaf area, plant height, and leaf chlorophyll of Eucalyptus species significantly repressed the growth of under growth plants (Ahmed et al., 2008; Zhang, 2009; Lisanework and Michelsen, 1993; Poore and Fries, 1985). Molina et al., (1991) reported that, Eucalyptus releases toxic allelo-chemicals into the soil system mainly through litter decomposition products. In this piece of evidence, Eucalyptus plantations affects crop production by releasing toxic allelo-chemical.

\section{Conclusion}

The wider existing evidence of Eucalyptus species has a negative effect on crop yield where it grows nearby crop lands by competing resource such as soil nutrient, water and shade effect of the trees. Similarly, it depletes soil minerals required by agricultural crops, the capacity of water in the area and competes with agricultural crops; it reduces ground flora resulting unsuitable for soil erosion control; Thus, there is an irritation that the potential ecosystem will be exhausted in the future because of the described worse environmental modification. But when we managed the species properly it has high economically and ecologically benefit to the people. Because recent studies indicated that planting of crops in clear-felling eucalyptus stands gave higher crop yield as compared to the adjust crop lands. In this regard, Eucalyptus is good to rehabilitate crop lands to reuse for annual crop production and more profitable for the small holder farmers but the species is not appropriate for mixed panting system with annual crops. Therefore, keeping the maximum distance of eucalyptus and crops is good for better production. Furthermore, Ethiopia has large area that is suitable for crop and tree production so by developing land use policy we can get a lot of benefit through planting Eucalyptus species in appropriate site. It is known Eucalyptus plantation has offered both negative and positive opinions from around the world in general and in Ethiopia too. Consequently, giving more attention in its management is very important for sustainable production of crops and eucalyptus trees. Finally, still there is uncertainty the influence of Eucalyptus species on crop yield and soil nutrients. Therefore, further studies needed to reaching the comprehensive understanding about the species.

\section{Reference}

Abebe, M., \& Tadesse, W. (2014). Eucalyptus in Ethiopia: Risk or opportunity? Ethiopian Institutes of Agricultural Research, Addis Ababa.

Ahmed, R., Hoque, R., \& Hossain, M. K. (2008). Allelopathic effects of leaf litters of Eucalyptus camaldulensis on some forest and agricultural crops. J. Forestry Research, 19: 19-24.

Alem, S., Woldemariam, T., \& Pavlis, J. (2010). Evaluation of soil nutrients under Eucalyptus grandis plantation 
and adjacent sub-montane rain forest. Journal of Forestry Research, 21(4), 457-460.

Bernhard-Reversat, F. (1999). The leaching of Eucalyptus hybrids and Acacia auriculiformis leaf litter: laboratory experiments on early Decomposition and ecological implications in Congolese tree plantations, France. Applied Soil Ecology. 12, 251-261

Birru, Y., Anteneh, A., \& Tadele, A. (2013). Expansion of Eucalyptus Woodlots in the Fertile Soils of the Highlands of Ethiopia: Could It Be a Treat on Future Cropland Use? Journal of Agricultural Science, 5(8):97107.

Chanie, T. et al. (2013). Eco-hydrological impacts of Eucalyptus in the semi humid Ethiopian Highlands: the Lake Tana Plain. J Hydrol Hydromech 61: 21-29.

Cole, R.J., \& Rapp, M. (1981). Elemental Cycling in Forest Ecosystems. Cambridge University Press, London. pp. 341-409

Desalegn, T., Adane, A \& Demel, T. (2014). Effect of Eucalyptus camaldulensis stand Conversion into Crop Production on Growth and Yield of Maize: the case of Koga Watershed Areas in northwestern Ethiopia. MEJS; volume 6(1):58-69.

EI-Amin, E.A., Diab I.E., \& Ibrahim S.I. (2001). Influence of Eucalyptus on some Physical and chemical properties of a soil in Sudan, Sudan. COMMUN. SOIL PLANT ANAL. 32, 2267-2278

Gindaba, J. (2003). Water and nutrient relations of selected tree species of Ethiopia. PhD Dissertation, Stellenbosch University, Stellenbosch, South Africa, pp. 180.

Gindaba, J., Rozanove, A., \& Negash L. (2004). Response of seedlings of two Eucalyptus and three deciduous tree species from Ethiopia to severe water stress, Ethiopia.201, 119-129

Heilman, P., \& Norby, R.J. (1997). Nutrient cycling and fertility management in temperate short rotation forest systems. Biomass and Bioenergy 14, 361-370

Jagger, P., \& Pender, J. (2003). The role of trees for sustainable management of less-favored lands: the case of Eucalyptus in Ethiopia. Forest Policy and Economics 5(1), 83-95.

James, F. (1999). Fertilization effects on interactions between above-and belowground competition in an old field, USA, 80, 466-480.

Janice, L., Travis, R., Alemayehu, W., Cathy, C., \& Atalel, W. (2016). Effects of exotic Eucalyptus spp. plantations on soil properties in and around sacred natural sites in the northern Ethiopian Highlands. Agriculture and food.

Kidanu, S., \& Stroosnider, L. (2004). Soil erosion and seasonal water use in Eucalyptus globulus based rotational agro forestry system on Ethiopian high landVertisols

Kidanu, S., Mamo, T., \& Stroosnijder, L. (2004). Eucalyptus - wheat interaction on Ethiopian Nitosols. Agricultural Systems, 80: 151-170.

Kidanu, S., Mamo, T., \& Stroosnijder, L. (2005). Biomass production of Eucalyptus boundary plantations and their effect on crop productivity on Ethiopian highland Vertisols. Agroforestry Systems 63, 281-290

Khybri, M.L. et al. (1992). Crop yields of rice and wheat grown in rotation as intercrops with tree species in the outer hills of Western Himalayas. Agroforestry Systems 17, 193-204

Kotowskil, W., Andel, V. J., Diggelen, V. R., Hogendorf, J., (2000). Response of fen plant species to groundwater level and light intensity, Netherlands. Plant Ecology, 155, 147-156.

Lane, P.N.J., Morris, J., \& Ningnan, Z. (2004). Water balance of tropical Eucalyptus plantations in southeast China, China.124, 253-267.

Lemenih, M. (2008). Temporal Changes of Biomass Production, Soil Properties and Ground Flora in Eucalyptus globulus Plantations in the Central Highlands of Ethiopia Doctoral Thesis Swedish University of Agricultural Sciences Uppsala 2008 Faculty of Natural Resources and Agricultural Sciences Department of Forest Soils Uppsala

Lemenih, M. (2004). Effects of land use change on soil quality and native flora degradation and restorationin the highlands of Ethiopia. PhD dissertation. ISSN 1401-6230, ISBN 91-576-6540-0, Swedish

Lemma, B. (2006). Impact of exotic tree plantations on carbon and nutrient dynamics in abandoned farmland soils of southwestern Ethiopia. PhD dissertation. Swedish University of Agricultural Sciences, Faculty of Natural Resources and Agricultural Sciences, ISSN 1652-6880, ISBN 91-576- 7257-1, Uppsala. 1-42

Lisanework, N., \& Michelsen, A. (1993). Allelopathy in agro-forestry systems: the effect of Cupressus lusitanica and three Eucalyptus species on Ethiopian crops. Agrofor Syst 21: 63-74.

Malik, R.S., \& Sharma, S.K. (1990). Moisture extraction and crop yield as a function of distance from a row of Eucalyptus tereticornis. Agroforestry Systems 12, 128-187

Mekonnen, K., Lemenh, M. \& Campbell, B. (2007). The role and management of Eucalyptus in Lode Hetosa District, Central Ethiopia. Forest tree and livelihoods 17(4), pp.309-323

Molina, A., Reigosa, M.J. \& Carballeira, A. (1991). Release of allelochemicals agents from litter, through fall, and topsoil in plantation of Eucalyptus globulus Labill. In Spain. Journal Chemical Ecology 17, 147-160. 
Palmberg, C. (2002). Annotated Bibliography on Environmental, Social and Economic Impacts of Eucalypts. FAO.

Pohjonen, V. \& Pukkala, T. (1990). Eucalyptus globulus in Ethiopian forestry. Forest Ecology and Management $36,19-31$

Poore, M.E.D. \& Fries, C. (1985). The ecological effect of eucalyptus. FAO Forestry Paper No. 59. FAO, Rome, Italy

Saberi, M. A. et al. (2013). Allelopathic Effects of Eucalyptus camaldulensis on Seed Germination and Initial Growth of four range species. Annals of Biol. Res. 4(1): 152-159.

Sunder, S.S. (1993). The Ecological, Economic and Social Effects of Eucalyptus. FAO Corporate Document Repository 1

Tchienkoua, M., \& Zech, W. (2004). Organic carbon and plant nutrient dynamics under three land uses in the highlands of West Cameroon. Agriculture, Ecosystems \& Environment, 104(3), 673-679.

Teketay, D. (2000) Facts and experience on Eucalyptus in Ethiopia and elsewhere: ground for making wise and informed decision. Workshop on Eucalyptus Dilemma, 15 November.

Turner, J.W. \& Lambert, M.P. (2000). Changes in organic carbon in forest plantation soils in eastern Australia. Forest Ecology and Management 133, 231-247.

Watson, K. (2000). The effect of Eucalyptus and Oak leaf extracts on California Native plants, California

Zegeye, H. (2010). Environmental and Socio-economic Implications of Eucalyptus in Ethiopia.Ethiop Inst Agric Res 2010: 184-205

Zerfu, H. (2002). Ecological impact evaluation of Eucalyptus plantations in comparison with agricultural and grazing land-use types in the highlands of Ethiopia.

Zhang, C. \& Fu, S. (2009). Allelopathic effects of eucalyptus and the establishment of mixed stands of eucalyptus and native species. For Ecol Manag 258: 1391-1396. 